\title{
Parir é natural
}

\section{Giving birth is natural}

\section{Parir es natural}

Marina Maria Ribeiro Gomes da Silva | marina.maria@icict.fiocruz.br

Fundação Oswaldo Cruz, Instituto de Comunicação e Informação Científica e Tecnológica em Saúde, Centro de Tecnologia da Informação e Comunicação em Saúde. Rio de Janeiro, RJ, Brasil.

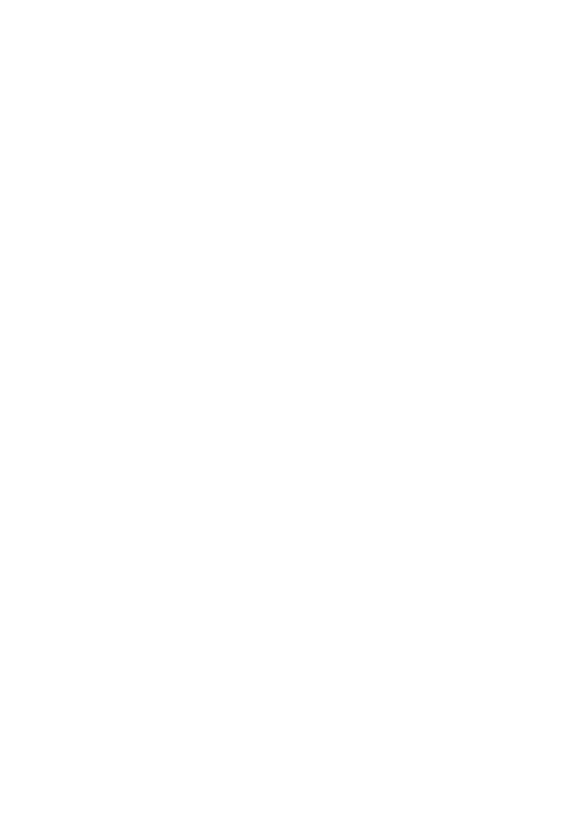

Imagem da capa do DVD Parir é natural

Palavras-chave: Documentário; Direito da mulher; Parto; Nascimento; Parto natural. Violência obstétrica; Maternidade; Parto humanizado. Saúde materno-infantil; Brasil.

Keywords: Documentary; Women's rights; Birth; Natural childbirth; Obstetric violence; Maternity; Humanized birth. Maternal and child health; Brazil.

Palabras clave: Documental; los derechos de las mujeres; nacimiento; parto natural; violencia obstétrica; la maternidad; Humanización del parto; salud de la madre y el niño; Brasil. 


\section{Parir é natural: potência das mulheres}

O documentário Parir é natural (2015), do diretor Silvio Tendler e realizado com apoio do Selo Fiocruz Vídeo, da VideoSaúde Distribuidora da Fiocruz, vem endossar as diferentes mobilizações em defesa do renascimento do parto como um evento fisiológico e do direito que as mulheres têm de vivenciar esse acontecimento com acolhimento, cuidado e respeito. O título soa quase como uma obviedade para a condição humana, se não fossem as intervenções desnecessárias e violações de que se tem conhecimento em partos, e se não estivéssemos num país campeão mundial de cesáreas, como aponta a pesquisa Nascer no Brasili, o que evidencia que nunca é demais lembrar que, sim, parir é natural.

No filme, estão reunidas gestantes, mães, profissionais de saúde e pesquisadores(as) que atuam no debate em defesa do parto humanizadoii e dos direitos sexuais e reprodutivos das mulheres no país e também no exterior, analisando impasses, desafios e possibilidades na busca de parir com dignidade, respeito e liberdade de escolha. Os depoimentos, as cenas de nascimentos e as histórias reunidas pelo diretor são, no entanto, um ínfimo recorte diante da pluralidade de experiências e contextos das mulheres no Brasil, seja numa perspectiva socioeconômica, cultural e racial, seja pelos seus desejos e suas expectativas individuais do parto. Retrata, especialmente, condições e vivências associadas a mulheres e profissionais que integram redes de apoio à humanização do parto em grandes centros urbanos, sem apresentar mais amplamente a realidade complexa do nascimento no país e as diferentes práticas evidentes.

Não por isso o documentário perde sua capacidade de inspirar, inquietar e, sobretudo, de ser um instrumento fundamental de informação e suporte às mulheres na construção de seus repertórios, referências e decisões no profundo percurso da maternagem. Neste sentido, Parir é natural aciona uma diversidade de reflexões e materializa múltiplas formas de potência, diretamente proporcionais à intensidade que é gestar uma vida, parir, nascer e renascer com a chegada de um(a) filho(a). E igualmente relacionadas à capacidade transformadora das mulheres.

É a partir dessas formas de potência que a presente resenha se constrói, dialogando com as falas, cenas e entrelinhas que constituem o filme, a começar pelo impacto da linguagem audiovisual na ampliação do

i Segundo dados da pesquisa Nascer no Brasil (2014), coordenada pela Fundação Oswaldo Cruz, o Brasil apresenta alto índice de cesarianas e, no setor privado, a situação é ainda mais alarmante. O estudo aponta que a cesariana é realizada em $52 \%$ dos nascimentos, e, no setor privado, o número chega a 88\%, em contradição com a recomendação da Organização Mundial da Saúde (OMS) de que somente $15 \%$ dos partos sejam realizados por meio desse procedimento cirúrgico e quando houver de fato necessidade. Ver mais em: http://portal.fiocruz.br/pt-br/content/pesquisa-revela-numero-excessivo-de-cesarianas-no-pais e https:// www.youtube.com/watch?v=Q9G5uyRKsyk

ii Segundo o Programa de Humanização no Pré-natal e Nascimento, do Ministério da Saúde, a humanização do parto prevê que as unidades de saúde recebam com dignidade a gestante, seus familiares e o recém-nascido, o que requer atitude ética e solidária por parte dos profissionais de saúde e a organização da instituição, de modo a criar um ambiente acolhedor e a instituir rotinas hospitalares que rompam com o tradicional isolamento imposto à mulher. Além disso, implica a adoção de medidas e procedimentos benéficos para o acompanhamento do parto e do nascimento, e reconhecimento do protagonismo da mulher neste processo, evitando práticas intervencionistas desnecessárias e que não beneficiam a mulher nem o recém-nascido. Ver mais em: http://bvsms.saude.gov.br/bvs/publicacoes/parto.pdf 
acesso à informação e do direito à comunicação. A potência do corpo das mulheres frente às inúmeras violações de direitos vivenciadas, as violências relatadas e as condições desfavoráveis para parir de acordo com a escolha feita, seja na rede privada da assistência à saúde, seja no Sistema Único de Saúde (SUS), também são discutidas. E, por fim, a potência das redes de apoio e o papel fundamental de grupos no fortalecimento e reconhecimento do protagonismo das mulheres no momento do parto, por meio de orientação, troca, reconstrução, acolhimento e suporte permanente no enfrentamento dos desafios também ganham destaque, como apresentado a seguiriii.

\section{A potência do audiovisual}

O filme Parir é natural torna-se um dispositivo fundamental não só para romper com a tentativa de silenciamento acerca de temáticas em torno das condições do parto oferecidas às mulheres no Brasil, mas também do direito sobre o seu próprio corpo, da capacidade de parir e da liberdade de decidir. Ao mesmo tempo que o depoimento da mãe que aparece no início do documentário, por exemplo, traz à tona a dor e o sofrimento pelo desrespeito vivenciado na hora do seu primeiro parto, com excesso de intervenções, exame de toque recorrente, falta de acolhimento pela equipe, entre outras situações de violência obstétrica, uma outra gestante, acompanhada de sua doula, sinaliza outro caminho possível de protagonismo, pautado no acúmulo de informação de qualidade sobre seus direitos e possibilidades.

A composição dessas falas, juntamente com as de obstetras, enfermeiras obstétricas, parteiras e mães, é conduzida pelo diretor rumo ao empoderamento das mulheres para reconhecer que podem parir naturalmente e fazer suas escolhas - embora estas sofram limitações impostas pelo cenário de desigualdades do país que não são amplamente problematizadas no documentário. Imagens de partos naturais mais acolhedores, de serviços de assistência e equipes com práticas de cuidado mais humanizadas se somam a esse potencial de informar para empoderar, chacoalhando também os telespectadores com evidências, dados científicos e questionamentos do biopoderiv. E dão uma luz ao importante debate sobre a formação médica no Brasil, nosso sistema de saúde e a construção da soberania do discurso biomédico, em detrimento de outros saberes e práticas mais tradicionais.

Outras tantas denúncias são apresentadas no filme, tais como a gravidade da epidemia de cesáreas ${ }^{\mathrm{v}}$ no Brasil e a tecnocracia nos partos, descrita por um dos médicos entrevistados. Segundo ele, ela segue a lógica de um sistema que entende o nascimento como linha de produção para a qual o parto natural é contraproducente. Além dos interesses econômicos em jogo, a formação médica é analisada no contexto da saúde materna, revelando que tem contribuído para tal entendimento restrito do ato de nascer, por incentivar que pacientes, em geral, sejam tratados a partir do que apresentam de patológico e riscos potenciais, e não de uma maneira holística e integral, em que as situações podem dar certo. Assim, intervenções como

iii Para elaboração desta resenha, o livro "Renascimento do Parto", de Michel Odent foi uma referência importante, no entendimento do reconhecimento do parto como um ato fisiológico².

iv Em linhas gerais, o conceito de biopoder, proposto por Michel Foucault ao analisar as formas de poder nas mais diversas relações, instituições e dinâmicas sociais, está associado à ciência e suas formas de interferência na sociedade. Em outras palavras, às formas de controle exercidas pela ciência sobre a vida das pessoas, com base em normas e regras relacionadas, sobretudo, ao corpo e ao saber. As ciências biomédicas são, assim, um desses mecanismos de poder que tentam normatizar a vida, regular e controlar corpos e mentes ${ }^{3}$.

v Dados do Ministério da Saúde revelam que a cesárea, sem indicação médica adequada, ocasiona riscos à saúde da mulher e do bebê, aumentando, por exemplo, em 120 vezes a probabilidade de problemas respiratórios para o recém-nascido e triplicando o risco de morte da mãe. Somente deve ser indicada nas situações em que o processo natural do parto apresenta complicações para a mulher e bebê e, na maioria das vezes, só é possível diagnosticar a necessidade durante o trabalho de parto. São raras as situações em que é necessário agendar a cirurgia antes do início desse processo de nascimento. Uma cesárea desnecessária, realizada com hora marcada pelo obstetra e a mulher, antes do trabalho de parto, pode provocar um nascimento prematuro do bebê, o que é preocupante, pois cerca de $25 \%$ dos óbitos neonatais e $16 \%$ dos óbitos infantis no Brasil são causados pela prematuridade. Ver mais em: http://promocaodasaude.saude.gov.br/promocaodasaude/assuntos/incentivo-ao-parto-normal/noticias/ partos-normais-e-cesareas 
a episiotomia (corte feito no períneo, região muscular entre a vagina e o ânus da mulher, para facilitar a passagem do bebê) continuam sendo ensinadas em escolas médicas como práticas regulares, quando evidências científicas sólidas, conforme lembra a obstetra e pesquisadora Melania Amorim no filme ${ }^{\text {vi vii }}$, apontam não serem sempre necessárias.

O documentário amplia ainda uma reflexão sobre a centralidade da participação do médico nos partos e propõe a inserção de outros profissionais nesse contexto, como obstetrizes, doulas e enfermeiras obstétricas, com a formação de equipes multiprofissionais. Depoimentos de enfermeiras obstétricas são articulados e denunciam os desafios que encontram ao prestar assistência a gestantes, falam das possibilidades de atuação e da restrita oferta do curso no país. A experiência inglesa com o trabalho das parteiras contribui para a ampliação desse debate e da defesa de que a mulher seja, acima de tudo, protagonista do seu parto ou, em outras palavras, que ela decida onde e como quer parir e receba informações dos profissionais que a acompanham.

Essa reflexão sobre as formas de assistência ao parto e as orientações compartilhadas por mulheres e profissionais, com base nas suas experiências, se apresentam em Parir é natural como inspiração e apoio bem-vindos. Neste sentido, o audiovisual se fortalece enquanto potência, pelo papel crítico, informativo, político e social que tem e pode ter, sobretudo, pelo alcance e pela visibilidade dada a pautas urgentes e veladas. É um aliado no acesso ao direito à informação e comunicação de qualidade para que o direito à saúde das mulheres seja assegurado.

\section{A potência dos corpos}

A avassaladora potência dos corpos é escancarada nas cenas apresentadas no filme, com barrigas já crescidas de gestantes, mulheres em trabalho de parto em meio a contrações ou parindo naturalmente, bebês em seus primeiros minutos de vida, ainda com os olhos entreabertos no primeiro contato com o mundo, mulheres em rodas de conversa sobre as suas experiências, mulheres com seus filhos e filhas se mobilizando por direitos. Corpo em movimento, pulsando, gestando. Mulheres em movimento, se expressando, reivindicando nas ruas, trocando, informando. Tal potência é revelada ainda nos relatos sobre violência obstétrica compartilhados, que falam de um corpo marcado pela dor, mas também pela resistência, força e resiliência em busca de novos repertórios.

A legitimidade desses múltiplos corpos potentes salta aos olhos nessas cenas e revela que acolher a intensidade e transformação vivida pelas mulheres, com suas angústias, dúvidas, expectativas e inseguranças, implica uma necessária revisão do ambiente e dos espaços destinados ao nascimento, bem como a oferta de cuidado de forma integral e o reconhecimento das demandas específicas de cada mulher. $\mathrm{O}$ filme evidencia ainda que as práticas de acolhimento precisam ser fortalecidas invariavelmente no contexto da saúde pública e dos serviços privados de assistência, sobretudo nesse último, dado o incentivo a cesáreas e o seu predomínio, conforme dados da Pesquisa Nascer no Brasilviii.

A busca de vivenciar um parto natural, compatível com a potência desses corpos, acaba sendo descrita como peregrinação em algumas cidades do país, diante da escassez de unidades de saúde alinhadas com uma política de humanização. Ao mesmo tempo, há casos em que as gestantes abrem mão da assistência disponível na saúde suplementar e optam por seguir seu pré-natal no SUS que, apesar das diferentes fragilidades que apresenta pela instabilidade nos padrões de cuidado e no atendimento ainda variável de

vi Para mais informações, ver artigo "Assistência ao primeiro período do trabalho de parto baseada em evidências", disponível em: http://bhpelopartonormal.pbh.gov.br/estudos_cientificos/arquivos/artigo femina_assistencia_ao_parto_parte_.pdf ${ }^{4}$.

vii Para mais informações, ver artigo "Assistência ao segundo e terceiro períodos do trabalho de parto baseada em evidências", disponível em: http://www.febrasgo.org.br/site/wp-content/uploads/2013/05/Feminav38n11_583-591.pdf 5 .

viii Como revelam a nota i e o filme Nascer no Brasil: o retrato do nascimento na voz das mulheres: https://www.youtube.com/ watch?v=kNZQnYn7PkE 
acordo com a equipe, oferece maior possibilidade de serviços humanizados. Uma das mães menciona que, em busca de um médico que fizesse parto natural pelo plano de saúde, chegou a entrar em contato com 18 obstetras conveniados. O resultado dessa saga foi a frustração por não ter encontrado nenhum profissional em que sentisse a segurança e a disponibilidade para apoiar um parto natural ou mesmo normalix. No final decidiu pagar a uma equipe comprometida com a prática humanizada que buscava.

Todas essas tentativas e buscas descritas no filme se relacionam à pauta da agenda feminista em prol da autonomia e direito das mulheres sobre o seu próprio corpo, conforme suas vontades, competências e potências. Parir é natural, e o parto deve ocorrer, acima de tudo, de acordo com a escolha, desejo, liberdade e condições de saúde de cada mulher. É fundamental não perder de vista que a gestação, pelo seu caráter biopsicossocial, é um processo amplo que envolve o pré-natal e o parto, mas em igual importância o puerpério.

Nesse sentido, o filme acaba indo ao encontro também das reivindicações que tomaram as ruas do país no final de 2015, em que mulheres se mobilizaram mais uma vez em defesa de seus corpos, em oposição às forças políticas conservadoras que tentaram aprovar no Congresso projeto de lei ${ }^{\mathrm{x}}$ com propostas de mudanças relativas ao atendimento a vítimas de abuso sexual, estabelecendo obstáculos ao aborto, legalmente garantido nesses casos no Brasil.

O filme mostra que a potência desses corpos das mulheres gera, por conseguinte, mais potência em um corpo em formação recém-nascido, que só aparentemente é frágil. Conforme descreve um médico no documentário, ao nascer, o bebê já precisa aprender a respirar sozinho, manter a temperatura do seu corpo, e se alimentar. Por conta disso, ele ressalta a importância de que as mulheres entrem em trabalho de parto, pois só assim o seu corpo sinaliza que já está na hora do bebê nascer e que as competências dele, por sua vez, são ativadas para viver fora da barriga da mãe.

\section{A potência das redes e os grupos de apoio}

O filme é permeado pela vivência de mulheres na trajetória construída em busca de suporte e orientações para parir naturalmente e não poderia deixar de destacar o papel das redes de apoio a gestantes neste em muitos casos, árduo - processo. Doulas, mães e famílias enfatizam a potência desses grupos em seus depoimentos, sobretudo como fonte de informação, partilha, acolhimento e fortalecimento para viver a profundidade e imprevisão do acontecimento do parto com a segurança necessária. Além disso, diante de todos os desafios do parto ativo e natural no país descritos ao longo do documentário, encontros de acolhimento da pluralidade de demandas das mulheres e para o intercâmbio de experiências, como os promovidos por essas redes, se consolidam como fundamentais antes, durante e depois da gestação.

Em Parir é natural, as cenas de atividades coletivas realizadas em casas de parto e em grupos de apoio à gestante apresentam caminhos e práticas mais alinhadas com a humanização, determinantes para a trajetória da mulher na maternagem e baseadas na empatia e na sororidade. E o que vemos é que toda essa potência dos grupos ganha ainda mais força e possibilidades com as novas tecnologias de informação e comunicação (TIC), que, a partir de blogs, sites e redes sociais pela internet, por exemplo, têm multiplicado os espaços de disseminação de informação e articulação entre gestantes e mães, abordando as mais diversas temáticas nesse contexto.

Assim, pelos relatos apresentados, o documentário reforça que mulheres seguem precisando do fortalecimento, orientação e cuidado que o encontro e a conexão com essas redes de apoio possibilitam, para seguirem, como relata uma das mães, na persistência feminina. Ou ainda, diz outra, em defesa de que

ix Em linhas gerais, tanto o parto normal quanto o natural são vaginais; a diferença é que o primeiro passa por intervenções como, por exemplo, o uso de medicamentos, enquanto o segundo prevê que o nascimento aconteça naturalmente.

x Trata-se do projeto de lei 5069/2013. Para mais informações, acesse http://www.naomekahlo.com/\#!O-que-muda-com-oPL-506913/c1a1n/562d7d680cf2c1279d5e7c84 
tenham voz para expressar suas escolhas com liberdade sobre o seu parto e corpo. Entretanto, apesar das possibilidades de acesso a essas ações por meio do uso das TIC nesse contexto, o seu alcance ainda é restrito e não contempla a diversidade de mulheres do país, em suas variadas condições socioeconômicas, culturais, raciais e territoriais.

Implementar medidas mais inclusivas para que as informações e toda a potência dessas redes de apoio alcancem mais amplamente mulheres e famílias pelo Brasil, de uma forma acolhedora, fica como desafio aos diferentes coletivos que surgem e se consolidam em torno da mobilização e de pautas que, muitas vezes, extrapolam a gestação, o parto, a amamentação e outras pautas do universo da maternagem. Principalmente para que o parto, no estado natural que o documentário apresenta e reafirma, possa ser vivenciado em sintonia com o reconhecimento das mulheres dos seus próprios direitos e de suas potências.

\section{Referências}

1. Lansky S, Friche AAL, Silva AAM, Campos D, Bittencourt SDA, Carvalho ML et al. Pesquisa Nascer no Brasil: perfil da mortalidade neonatal e avaliação da assistência à gestante e ao recém-nascido. Cad. Saúde Pública [Internet]. 2014 [citado 06 fev. 2016] ; 30(Suppl 1): S192-S207. Disponível em: http:// www.scielo.br/scielo.php?script=sci arttext\&pid=S0102-311X2014001300024\&lng $=e n$

2. Odent M. O renascimento do parto. Florianópolis: Saint Germain; 2002.

3. Foucault M. Microfísica do Poder. Rio de Janeiro: Edições Graal; 2003.

4. Porto AMF, Amorim MMR, Souza ASR. Assistência ao primeiro período do trabalho de parto baseada em evidências. Femina [Internet]. 2010 [citado 06 fev. 2016]; 38(11): 527-37. Disponível em: http:// bhpelopartonormal.pbh.gov.br/estudos cientificos/arquivos/artigo femina assistencia ao parto parte I.pdf

5. Porto AMF, Amorim MMR, Souza ASR. Assistência ao segundo e terceiro períodos do trabalho de parto baseada em evidências. Femina [Internet]. 2010 [citado 06 fev. 2016]; 38(11): 583-91. Disponível em: http://www.febrasgo.org.br/site/wp-content/uploads/2013/05/Feminav38n11 583-591.pdf 